\title{
The political risks of technological determinism in rural water supply: a case study from Bihar, India
}

\begin{abstract}
With the politics of the environment so fundamental to the development process in rural India, this paper analyses the relations between water discourses and drinking water technology. First, the national discourses of water are analysed using key policy and populist documents. Second, the paper presents ethnographic fieldwork studying the politics of drinking water in rural Bihar, where the relative merits of borehole handpumps and open wells are contested. The links between the national discourses and local contestation over appropriate technology are examined. The paper argues both policy and traditionalist perspectives are too technologically deterministic to adequately account for the myriad challenges of delivering rural water supply. The emphasis on technology, rather than service levels, creates the conditions in which capability traps emerge in terms of service provision. This is not only in terms of monitoring regimes but in the very practices of rural actors who use certain water supply technologies under an illusion of safety. With a focus on furthering the policy debate, the paper considers ways forward and suggests that a move from a binary understanding of access to a holistic measure of service levels will reduce the potential for political contestation and capability traps in rural water supply.
\end{abstract}

Key words: Rural water supply; Policy; Technology; Discourse; Institutions; India

*Author details and acknowledgements have been removed from this version. 


\section{Introduction}

In the debate that followed the global achievement of the Millennium Development Goal (MDG) 7c for water supply (JMP-WHO/UNICEF 2012), researchers have questioned the classifications used in the WHO/UNICEF Joint Monitoring Programme for Water Supply and Sanitation (JMP) (Clasen 2012; The Lancet 2014). Access figures from the JMP indicate that nearly $90 \%$ of the global population consume water from an improved water source whilst around $10 \%$ are reliant on water from an unimproved source (JMP-WHO/UNICEF 2012). The distinction between improved and unimproved sources is based on the probability that certain types of water sources are more prone to contamination by faecal matter, the leading cause of water-related morbidity and mortality. Improved sources, such as boreholes with handpumps, are deemed secure from such contamination by the nature of their construction whilst unimproved sources, such as open hand dug wells, are considered to have little protection against such contaminants (JMP-WHO/UNICEF 2014). This simple classification has enabled the widespread and consistent monitoring of water supply access throughout the world (Bradley and Bartam 2013) and, as has been the case with many international policy targets (Velázquez Gomar 2014), become a powerful unifying goal that has helped mobilise the international community. Yet, in its current formation, the MDG target does not take into account the service levels that people receive from their water supply. Considering this omission in the context of meta-analysis data that indicates that $28 \%$ of the global population consume water that fails to meet World Health Organisation (WHO) water quality standards (Onda et al. 2012), it means that over one billion people consume water that is technically unsafe but classified as 'improved' access in the MDG figures. In this sense, the proxy indicator for water supply poorly reflects the actual service levels many people experience. 


\section{Unpublished manuscript}

It has been argued that the significant political risk of this 'metric problem' is that, by significantly overestimating access to safe water, the global monitoring figures could lead to a reallocated of resources away from the water sector, "thereby putting at risk continued progress on critical health goals that depend on ensuring sustainable access to safe drinking water" (Clasen 2012, p. 1180; Bradley and Bartam 2013; The Lancet 2014). There is also evidence that having a technologically-deterministic indicator detrimentally shape the goals of water policies and programmes, leading to an overemphasis on expanding access through infrastructure development, and a neglect of broader investments in maintenance and institutional development, which are both critical to ensuring sustainable supply (Moriarty et al. 2013). Despite the articulation of these macro and programmatic concerns, there has been surprisingly little engagement within the academic literature on the role of the MDG discourse in shaping the behaviour of actors at an implementation level. This is despite of a well-theorised body of literature that examines the tensions between standardised policy discourse and the reality of local complexity in development programmes. Such work has famously shown the limitations of "seeing like a state" (Scott 1998, p.1-8), particularly in rural regions, where the governance requirements for standardisation have often bred resistance from local actors as it fails to account for the high degree of variability in local customs and practices (Scott 1998; Gupta 1998; Birkenholtz 2008).

More broadly, the emphasis on technology in the policy discourse also enables this contribution to relate to wider debates about technological determinism. The notion that technology drives history is a key facet in social thought, for example, reflected in Karl 


\section{Unpublished manuscript}

Marx's notion that the technologies of production drive societal change (Mackenzie, 1984). The distinction between hard and soft (technological) determinists is of significance here (Roe Smith and Marx, 1994) where hard determinists have a reductionist view of history whereby the trajectories of technological innovation drive historical change and are beyond social, cultural and political influence. Conversely, soft determinists note the potential for social, cultural and political forces to shape the trajectories of technological innovation, yet emphasise that technology remains one of the primary driving forces in human history. In this sense, a technological discourse can reflect different balances of hard or soft determinism that can either embody the material technology with a simple, non-challengeable causal agency, or place it within a more complex setting whereby non-material factors, such as behaviour and practice, can also influence outcomes. These concepts of hard and soft determinism are thought to provide a particularly useful distinction for assessing the use of water discourses in India as the paper explores the extent to which technology is constructed as part of a broader storyline about water and development or as the end goal in itself. This contribution engages with these debates as it examines how social movements and activists actively challenge technocratic policy discourse in India by drawing on alternative notions of good practice in rural water supply (Agarwal and Narain 1997; Jacob 2008; JJJA 2012). In particular, these critiques often exhibit what can be crudely labelled as a traditionalist-environmental discourse that can promote the use of "unimproved" indigenous technologies, such as open wells (for example, see: MPA 2011). In this way, they directly call into question the legitimacy of improved/unimproved demarcation but as is argued in this paper such actors retain a technologically deterministic approach in doing so. This paper examines the components of such discourses at a national level in India in order to consider the tensions 
between these contrasting notions of appropriateness in the rural water supply sector. Then, building on ethnographic fieldwork, it describes a case in which this battle for legitimacy plays out at the implementation level in West Champaran district in Bihar state. The paper concludes with a discussion in which the findings are considered in relation to theories of policy-making and institutional change with questions raised about the value of deterministic discourse at an implementation level.

\section{Approach to understandings discourses of water and technology in India}

Discourse analysis covers a broad set of approaches that range from the purely linguistic analysis of texts to the socio-theoretical 'Foucauldian' school of analysis (Fairclough 2003). With the idea that different modes of discourse analysis fit specific purposes (Gee 1999; Doulton and Brown 2009), this research considered a number of inter-related contributions. It recognises the tradition of discourse analysis in international development studies (Faille, 2011). In particular, Escobar's (1997) seminal work on the discourses of underdevelopment in which he connects the notion of underdevelopment with a legitimization of continued Western hegemony and interventionist policies around the world. In a similar way, Ferguson (1990) uses the approach to criticise technocratic discourses in development projects as part of the "anti-politics machine" that is used to conceal political decisions regarding societal change by using apolitical managerial speak. Such contributions offer critical insight into the power of discourse analysis for unrevealing underlying and unconscious structures of power in society. However, as argued by Faille (2011) the underlying methodology of much discourse analysis in international development is considered marginal to contributions made from broader subject areas, such as environmental policy studies. 


\section{Unpublished manuscript}

This research fuses the spirit of discourse analysis from the international development studies literature with the more established discourse analysis approach of Dryzek (2005) and Hajer (1995) who both offer seminal approaches to the analysis of environmental policy discourse. These approaches have proved particularly useful because they help answer politically important questions regarding how notions of responsibility and rights are constructed (Hajer 2002, p.18). Here, discourse is defined simply as a "shared way of apprehending the world" which is embedded within language (Dryzek 2005, p.8). From this perspective, discourse analysis is about identifying the key components of discourse such as its modes of knowing, ontological assumptions, models of causality, relevance judgements (of agents), and shorthand storylines. To identify these components, Dryzek (2005) asks four key questions: What are the basic entities recognized or constructed in the text? What assumptions does it make about natural relationships? Who are the agents and what are their intentions? What key metaphors or rhetorical devices does the discourse make use of? Using these questions, we analyse the Government of India National Water Policy (NWP) (2012) and the Jal Jan Jodo Abhiyaan (JJJA) (2013) campaign documents, both of which were formally released in April 2013 with the first author present at both launch events in New Delhi. The NWP text represents the principle-positioning document for government policy, whilst the JJJA manuscript sets out the aims of a prominent pan-Indian traditionalist movement reflecting an archetypal representation of a traditionalist storyline at a national level. The process of coding and analysis was conducted on English language copies of these documents only and is presented in the following section. However, drawing on the work of Hajer (1995), the research also moves beyond a purely linguistic analysis of these texts, to a broader approach that recognises discourse coalitions of actors share and use a discourse (or discourses) to 


\section{Unpublished manuscript}

construct particular storylines. This framework places actors within the realm of discourse where discursive affinity can hold together a coalition of actors who share argumentative structures that contribute to a particular storyline, even if they emerge from different sources and logics, or operate in different domains (Feindt and Oels 2005; Hajer and Versteeg 2005). In this regard, the research sought to assess the use and function of the policy and populist discourses at the implementation level of rural water supply.

The lead author conducted fieldwork during five weeks in April and May 2013 in West Champaran district in Bihar state in northern India. Initially, fifteen key informant or "helicopter" (Hajer 1995) interviews were conducted both remotely from the UK and face-toface in India with policy makers, practitioners and activists to help understand the role of these discourses in the Indian sector. This was followed by ethnographic fieldwork shadowing workers from two NGOs, Megh Pyne Abhiyan (MPA) and its local partner Water Action. Both these organisations work "towards alternative and sustainable drinking water and sanitation security" in North Bihar (MPA 2011). The context for the fieldwork can thereby be classified as an extreme case (Flyvbjerg 2006) as it provides a window into the operations of grassroots organisations who actively challenge the dominant policy storylines about rural water supply. Following the "common-sense" approach urged by Chambers (2008) for village-level ethnography, intersect walks, group interviews, informal conversations with community members, as well as participant observation of village drinking water and sanitation arrangements were conducted in villages visited with the NGOs. Such an approach provided the flexibility for the researcher to observe, engage and react to local actors, providing space for dialogue and reflection. Data was recorded through 


\section{Unpublished manuscript}

ethnographic notes that were initially written up after each conversation and then expanded on each evening during the trip. Through coding of 138 pages of interview and ethnographic manuscripts an analysis was conducted that provides the empirical material that is summarised in Section 4. Ethical approval for the fieldwork was sought and received from the relevant University ethics committee.

A broadly institutional perspective has been used to analyse the fieldwork data, bringing together theories of institutional change (Cleaver 2002; 2012; Andrews et al. 2013; Pritchett et al. 2013), with the previously introduced understanding of discourse taken from the work of Hajer (1995) and Dryzek (2005). Institutions are considered central to understanding technology use as they are the enduring social structures and patterns that shape and regulate human behaviour with some degree of purpose (Merrey et al. 2007, p.196): they include both organisations, such as the government and NGOs, but also the "complexes of norms and behaviours" with some degree of permanency that produce collectively valued outcomes, such as a norm that a certain technology is appropriate to a given context (Uphoff 1986, p.89; Cleaver 2012). Based on the work of Cleaver (2012), discourse is considered an important legitimising resource that actors can use to shape institutional change leading to material outcomes in rural communities. This approach builds on the work of the anthropologist LeviStrauss (1966) to understands institutional change as a process of bricolage in which bricoleurs (agents) draw on a mixture of locally-embedded and externally-imposed norms to shape institutional change (Cleaver 2002; 2012). For our purpose, this perspective illuminates how discourse often becomes reproduced in new and varied ways by actors at a local level leading to unintended outcomes from externally imposed policies and programmes. In the 
paper, we relate such mechanisms to a broader theory of institutional change that emphasises the potential for isomorphic mimicry (Pritchett et al. 2013) and capability traps (Andrews et al. 2013) in development. The former term is used to describe a process in which the encouragement of prescriptive best practice leads to changes in what institutions look like but not in underlying function, whilst the latter phrase refers to the outcome of this process, as the change in the appearance of the institution negates the impetus for real reform thereby perpetuating the existing problem and creating a capability trap (Pritchett et al. 2013). Together these bodies of work have been used to describe the often seen mechanics of failure in development when some kind of standardised best practice is promoted in a context without fully considering the embedded institutional landscape and, continuing in this tradition, these terms prove useful in explaining the situation that emerges in Bihar. Such debates are revisited in the later sections of this paper.

\section{Examining the policy and traditionalist discourses of water in India}

Both the National Water Policy 2012 (NWP) and the Jan Jal Jodo Abiyaan (JJJA) documents construct storylines about the state of India's water resources that have connotations for rural water supply. A less radical reading is developed by the NWP, which positions the oftenreported problems with Indian water as the product of "mismanagement". This suggests they are resultant from anthropogenic (mis)action, yet implies that responding to any problems is within reach of the current paradigmatic approach to water resource management. So, as an illustration, the NWP states: "Issues related to water governance have not been addressed adequately. Mismanagement of water resources has led to a critical situation in many parts of 


\section{Unpublished manuscript}

the country" (p. 1). Drawing on reform-orientated paradigm it calls for improved governance and regulation as ways to address the situation. In responding to the limitations of previous forms of management, the policy promotes an adaptive strategy as a means for controlling the complexity of the aquatic environment. It draws on discourse from the water management and scientific epistemic community: "Planning, development and management of water resources need to be governed by common integrated perspective considering local, regional, State and national context, having an environmentally sound basis, keeping in view the human, social and economic needs" (p. 5). The policy dedicates a section to the need for a unified "Database \& Information System" stating that "all water related data...should be integrated with well-defined procedures and formats" (p. 29). In these and other ways, the NWP implicitly positions responsibility for managing water at a state or managerial level, where the surveillance of the entirety of the river basin can best be achieved.

Specifically for rural drinking water the NWP makes use of the improved and unimproved discourse that structures the principles of global water supply policy, stating that "efforts should be made to provide improved water supply" (p. 25). It goes on to expand these principles by saying that water for drinking and sanitation are "pre-emptive needs" that should take priority over other allocations, indicating an anthropocentric yet socially conscious agenda (p. 7). These extracts demonstrate the rhetorical reflexivity of the modern state, although critics may argue that it is actually a tactic characteristic of how powerful actors negate critique and revolutionary forces, as some argue has happened in relation to environmental discourse in the Western world (Christoff 1996). On the politically sensitive matter of pricing water, the NWP explains "the principle of differential pricing may be 


\section{Unpublished manuscript}

retained for the pre-emptive uses of water for drinking and sanitation; and high priority allocation for ensuring food security and supporting livelihood for the poor. Available water, after meeting the above needs, should increasingly be subjected to allocation and pricing on economic principles" (p. 17). This pricing of water is warranted to "ensure efficient use and reward conservation" and should be overseen by an "independent statutory Water Regulatory Authority" (p. 17). The NWP therefore aligns effective water resource management with the principles of economic valuation but stresses the "principle of equity and social justice must inform use and allocation of water". In summary, the policy exhibits a discourse that must be understood as the mainstream storyline regarding water and development in India. It is used by a wide range of actors with particularly important groups being government bureaucrats, development consultants and scientists. In a similar manner to Ferguson's (1990) notion of the anti-politics machine, it is rooted in a technocratic ideology that constructs decisions about water as issues of managerialism. Through this notion of depoliticized decision-making the actors that use it engender a dominant coalition that can claim an indisputable legitimacy in this domain of water management. However, the discourse only exhibits what can be described as a soft technological determinism as it references the need to shape technological solutions to "human, social and economic needs" (p. 5) and emphasized the role of political institutions, such as the state, in shaping such solutions.

In contrast, the JJJA document opens with a powerful statement of ambition that encapsulates the aspirations of the movement. It directly challenges notions of state control over water, instead evoking the importance of an individual's rights and responsibilities over rural water resources: "Strengthening people's capacities to cope with livelihood pressures, to regain rights and responsibilities over traditional water resources, and to create interest for 


\section{Unpublished manuscript}

regenerating tanks" (p. 1). In this way, it develops a historical narrative drawing on the timeless nature of water. It then summarises a further revolutionary objective: "Providing drinking water security to all, connecting people to natural resource conservation, enhancing their capacity to cope with impacts of climate change and starting a process of change that builds society based on principles of equity, justice and freedom from greed" (p. 1). In positioning the struggle for water as an arena for wider socio-political transformation, the movement projects a radical viewpoint. Such tendencies are also reflective of the environmental perspectives of some variants of Western environmentalism, however to move beyond "freedom from greed" (p.1) evokes a powerful metaphor of liberation from the world struggles of modern life, mirroring the teaching of Hinduism and other South Asian religions. In this way, the JJJA text makes use and draws authority from the religious discourse of South Asia and, it is supposed, that through this alliance gains greater legitimacy in the public sphere.

In a recent speech, the leader of the JJJA movement, Rajendra Singh - known as the "Waterman of India" in the national press (Shan 2010) - offers a stinging commentary of government policy: "Today if Gandhi ji would have been alive then he would be the first person to stop the control of our natural resources...Because water is a common natural resource: the basis of life. How could any Government ever think of giving the control of this natural resource to a company or an individual?" (Singh 2013). Aligning himself with Gandhian ideals, he nods towards the quintessential rural Indian narrative of self-sufficient village republics operating largely outside the modern system of private property. This is representative of a traditionalist discourse that deeply resists the commodification of nature in all forms, rejecting arguments regarding the utility of valuation as a tool for management, 


\section{Unpublished manuscript}

which underpins the approach of modern discourses of ecosystem services. Whilst built around the ideals of a romantic pre-colonial India, ontologically the discourse recognises the global threat of climate change, which is ironically made knowable by the modern forms of global environmental monitoring which are themselves enabled by the large scale surveillance aspired to by the NWP. In summary, the traditionalist discourse represented by the JJJA document is part of an alternative yet still mainstream storyline about natural resources in India. A diverse collection of actors employ the discourse including activists, spiritual leaders and politicians often in the context of anti-imperialist (and nationalist) criticism of industrial development. Through its application these actors seek to engender a coalition that helps reveal the political nature of development by challenging the technocratic and managerialism policy discourse that they perceive to be imperialist. The JJJA storyline is not technologically deterministic as it places political struggle as the primary force for change and only relates this to technology in a secondary sense, for example, with the use of traditional technologies following such struggles.

So, whilst the NWP and the JJJA texts share discursive affinity regarding the need to reform water management they draw on distinct discourses of water to create opposing storylines about who is responsible for rural water supply. The NWP speaks of mismanagement and the requirement for better data to support state-backed management, whilst the JJJA evokes the importance of local duty and the need to connect people to nature. These differences in terms of scale and responsibility are mirrored by the divergent nature of change they support. Revolutionary and radical, the JJJA makes use of the so-called water crisis to call for a fundamental societal shift including the rejection of material greed. Contrastingly, the NWP 


\section{Unpublished manuscript}

maintains a reformist agenda, built on amending planning, development and management principles in line with the latest technical guidance and industry best practice. The authority from each discourse coalition thus stems from distinct areas, with the JJJA drawing on history and conceptions of the local, and the NWP drawing on science and the recognisable institutions of modern political economy, principally the state and the market. This divide shapes the rhetorical contestations over rural water policy that occurs at a national level. However, as will be shown, these discourses also become reproduced in the material contestations over appropriate development in the rural communities of North Bihar.

\section{Technologies and practices of rural water supply}

Shifting from national positioning documents that seek to influence debate over water management and rural water supply, this section focuses to a grassroots example of contestation in West Champaran district, Bihar. West Champaran is the poorest district in the poorest state of India with $76.9 \%$ of the population living below the poverty line (Chaudhuri and Gupta 2009). Positioned in the far North West of Bihar it borders Nepal and Uttar Pradesh and is known as part of the "Red Corridor" of territory where the Naxalite-Maoist insurgency operates (Singh 2008). The Himalayan Mountains lay to the north so when monsoon rains combine with the summer snow melt floods can sweep the district (Sinha 2011), although normally less severely than in other districts of North Bihar. Government efforts to mitigate these floods through embankment building programmes have proven unsuccessful and have attracted criticism for being poorly planned and merely adding to existing problems (Prasad et al. 2012; Somanathan 2013). This economic, political and environmental insecurity shape the development process and provide the broad context that frames the discursive contestations over water and development found here. 


\section{Unpublished manuscript}

Across West Champaran, boreholes with handpumps are the most common form of rural water supply technology with $95.6 \%$ of people using one as a primary water source (Mukunda Das et al. 2013). As prescribed by the JMP, the Bihar state government and nodal agencies are committed to expanding improved forms of water supply and have helped install over 600,000 of these handpumps in recent decades. However, this trend has been even stronger in the private sector with an estimated six privately installed handpumps for every government provided pump across the state (Srikanth 2013). Household investment in improved water supply is in many ways the Holy Grail of rural water policy. However, representatives from the host NGOs are questioning this assumption. "Handpumps disconnect people from their environment. They've changed their behaviour leading to the degradation of alternative sources, particularly open wells", explained one interviewee. Another NGO practitioner summarised his view that: "handpumps have made the people lazy". Delving into this argument, these interviewees explained that when villagers used open ring wells there was a communal responsibility for the water source and therefore better incentives to maintain good environmental conditions in villages. With the introduction of handpumps, the balance of responsibility and incentive that held these practices in place fell away and people changed their behaviour and therefore the prevailing arrangements for environmental management degraded in the villages. Whilst testing the veracity of such statements would require longitudinal studies, it is notable that the characteristic discourses of the traditionalist movement are woven deep into such a narrative. Summarising the storyline about dug-wells, the NGO booklet explains that they "were an intrinsic part of northern Bihar village life" that are supported by "indigenous practices of well upkeep interwoven with tradition", yet all this 


\section{Unpublished manuscript}

has been eroded when "the state government began touting handpumps as the panacea for all water problems" (MPA 2011, p.36-37). This explanation shares discursive affinity with the JJJA storyline, with its emphasis on self-sufficient communities and the preservation of traditional water resources, constructed in contrast, and as an alternative, to state policy. This discursive viewpoint has translated into a work programme for the NGOs that involves reviving open wells, rainwater harvesting, and supporting the local production of ceramic water filters, alongside work on the promotion of alternative sanitation solutions such as ecosanitation toilets.

Yet in the villages when community members were asked about household preferences for different water sources, the themes that emerged were centred on convenience and affordability with an overwhelming preference for handpumps over open wells. This manifested in a number of ways. In the context of wider livelihood pressures, community members expressed the desire to minimise the labour involved in fetching water. Having a private or close-to-household source made the everyday routines of washing, cooking and other domestic duties more convenient as they could be conducted in an ad hoc fashion without prior planning. On the issue of cost, it was explained that the high water table, favourable geological conditions for drilling, and lower unit costs of certain types of handpumps, means that low-lift handpumps - known locally as chapakals - are available to even the poorest rural households. In this way, the discursive storyline utilised at the community level differed considerably from the traditionalist discourse by emphasising the positive aspects of a reduction in household labour invested in managing water resources. Rather than making users "lazy" and "dependent", both male and female community 


\section{Unpublished manuscript}

members emphasised the liberating aspects of this shift in water management practices. The discourse regarding the collapse of historic management practices was therefore not apparent at the community level but was restricted to certain professional actors operating in these communities. The lack of discursive affinity between the storylines of villagers and the NGOs on this particular issue was accepted by the practitioners, with them acknowledging "the lure of the handpump was not easy to rid" as they faced "tremendous resistance" in promoting open wells (MPA 2011, p.37). Despite this difference, they suggested that their concerns were legitimate and based on their own experience of witnessing "imported solutions" and "prescriptive policies" that have been uncritically imposed into local practices. In particular, they argue that a dangerous illusion has occurred whereby handpumps are constructed as a safe technology following the binary logic of the improved/unimproved discourse, rather than as a water source that tends to be safer in terms of biological contamination when managed in the correct manner. This is a subtle difference yet it is important as the standardisation of the discourse appears to mask the reality of a more complex situation and this is in-part shaping the behaviours of handpump users who have an unrecognised exposure to water-related risks.

Confirmatory evidence for this was forthcoming from transect walks when villagers justified poorly maintained handpumps with no sanitary seal or concrete apron in unhygienic conditions on the basis that the handpump "is safe as the water comes from the ground". Whilst this statement is broadly correct in sentiment, it is problematic as the relative quality of the handpump and the state of the immediate environment are key determining factors in influencing faecal contamination rates (Lloyd and Helmer 1991). The danger of "short- 


\section{Unpublished manuscript}

circuiting" whereby poorly constructed installations with no sanitary seal provide a direct pathway for surface contamination to enter the borehole is a particular risk (Godfrey et al. 2006), especially in areas with heavy rainfall or floods like West Champaran. Beyond the unacknowledged biological contamination risk, the NGO practitioners also claim that the handpump is exposing users to new water quality risks that were not previously seen in the district, noting that "since the introduction of handpumps iron marks people's teeth whilst skin problems related to arsenic are increasingly visible". The emergence of such geogenic water quality risks are being linked to the introduction of the handpump despite Government data indicating the district is free from such naturally occurring contamination (Srikanth 2013). The national leader of one of the host NGOs explained that he no longer trusts the Government data but recognises that evidence is needed to convince others of the validity of such claims. His NGO therefore commission its own water quality testing that indicates remarkable - though not peer-reviewed - results. It claims that $73 \%$ of borehole handpumps yielded water with iron beyond the $0.3 \mathrm{mg} / \mathrm{l}$ regulated limit compared to $20 \%$ of dug wells, whilst $24 \%$ of handpumps had arsenic levels above the $0.05 \mu \mathrm{g} / \mathrm{l}$ limits compared to $14 \%$ of ring wells (MPA 2012). Further investigation would be needed to confirm the veracity of this data and it is clear that peer-reviewed literature strongly suggests borehole handpumps have, on average, better water quality than dug wells (Parker et al. 2010), however the discursive relevance is not in the quality of the data but in its illustration of how these local actors are disrupting the universalistic nature of the policy discourse by constructing a localised, scientific-evidence base. The case therefore reflects how water policy discourses can become a point of contention when they become uncritically reproduced in new arenas. This process remains important to understand as the net result is a draining of energy and resources from 
the sector that could be better utilised responding to the myriad water-based problems facing India.

\section{The political risks of technological determinism}

We start the discussion by reminding ourselves that the underlying concern with the 'improved' metric is that it leads to a public health risk as the water provided through such installations often fails to meet basic water quality standards (Onda et al. 2012). This situation has already been connected to the significant political risk that the indicator contributes to an overestimation of progress towards the MDGs, which could lead to a premature and damaging diversion of resources away from water supply (Clasen 2012; Bradley and Bartam 2013). However, this study goes further by highlighting an additional risk connected to the improved/unimproved discourse that is manifest in parts of rural India. Here, the legitimacy of the discourse becomes contested by actors in the sector who make use of traditionalist discourse to construct alternative notions of appropriateness in terms of water supply. For example, in Bihar, the revival of dug wells and the promotion of "indigenous practices of well upkeep" are presented in direct competition with "the state government...touting handpumps as the magic bullet to address the water crisis" (MPA, 2011, p.37). It is possible to unpack how this contestation emerges by drawing on Bradley and Bartam's (2013) arguments that the improved indicator is the result of political discourse being rationalised: first, in the professional domain into a manageable target and, second, in the operational domain whereby the technical constraints of measurement lead to the binary standardisation of the discourse. The opposition emerges in Bihar because the "operational 


\section{Unpublished manuscript}

discourse" is no longer treated as a probabilistic indicator but rather as the normative goal in itself. In this way, the contestations of water supply at this grassroots level follow the logic of hard determinism, whereby the technology is embody with a kind of causal agency that will determine outcomes, rather than being part of a broader situation in which material and nonmaterial factors, such as behaviours and practices, come together to shape the safety of the water supply.

Building on this thinking, the conflation between an operational discourse and the normative goals of water supply creates the conditions for isomorphic mimicry (Pritchard et al. 2013) to occur eventually leading to a capability trap (Andrews et al. 2013). The policy aim of providing safe and sustainable water becomes operationalised as the provision of certain technologies but this does not necessarily change the underlying characteristics of the service, especially with regards to water quality. However, in contrast to the contrived nature that is implied in accounts of isomorphic mimicry in the state-governance context, in which actors intentionally navigate the institutional environment to create the appearance of change whilst minimising genuine adaptation (Pritchard et al. 2013), what we witnessed in Bihar is better conceptualised as a naïve form of isomorphic mimicry. Users adopt the improved technology for various reasons, especially the convenience of handpumps vis-à-vis open wells, so it is not the intentional manipulation of this process to gain some kind of legitimacy or resources. Yet, the result is all too often a capability trap as the provision of the improved technology does not correspond well with the ultimate policy goal of safe and sustainable drinking water. It is this gap that frustrates the NGOs witnessing these mechanics on the front-line and which

provides the justification for opposing what seems like externally imposed solutions that are 


\section{Unpublished manuscript}

not leading to intended outcomes.

However, the irony is that as the NGO develops its criticism of the what it perceives to be the 'hard' technologically deterministic approach of the government, by promoting its own hard determinism which the outright rejection of a certain technology that in many cases is desired by the local communities and which can serve them well in certain situations. In this sense, we must stress that at the implementation level both discourses studies in this paper are considered to exhibit a hard determinism that fails to adequately account for the myriad challenges of delivering rural water supply. The move back to dug-wells is highly unrealistic and goes against the preferences of the local population, whilst the notion that having a handpump (or other improved technology) equates to a safe water supply is equally untenable when many installations are poorly constructed and maintained. Responding to this situation, with a particular emphasis on the policy perspective, we argue that an alternative emphasis is needed which is more realistic about technology use at a local level. The recently revived anthropological concept of bricolage provides one possible approach (Levi-Strauss 1966; Cleaver 2002; 2012; Duymedjian and Ruling 2010). Often presented in contrast to a rationalistic-engineering model of predictable human behaviour (Duymedjian and Ruling 2010), bricolage suggests that people generally muddle-through problems drawing on available resources in highly contextual ways. Such an understanding implies that users adopt, adapt and use technology in many ways that are often sub-optimal in terms of performance: in Bihar, this includes handpump owners not investing in sanitary seals, whether out of choice or due to the limitations of funds, as well as people shunning labour intensive technologies such as dug wells. 


\section{Unpublished manuscript}

In reflecting on what this move to a more realistic discourse actually means in terms of the policy discourse, then the role of metrics is considered central. Although measurements categories are only a partial element of a broader policy discourse, they shape the water sector by determining the incentives for influential actors, such as governments and donors. Bartram (2008. P283-284), in a commentary in Nature, argues that the MDG targets for water [and sanitation] have "a basic weakness in regarding every human as either 'having' or 'not having' these key amenities; a formula well past its sell-by date...There is no real incentive for nations either near the top or the bottom of the international spectrum to tackle their water and sanitation challenges — because the current 'reward structure' is not set up to recognize the range of steps they could take to improve health". This critique is part of a broader discussion about shifting monitoring in water supply for the SDGs and beyond from its current focus on technology and coverage to a focus on services and service levels (for example, see: Slaymaker and Fonseca, 2012). This paper adds further credence to these arguments by showing the perverse implications of a focus on technology as a proxy indicator of success in such a politically-sensitive sector. In this sense, the work supports a move from a discourse of access to a discourse of service levels, such as those proposed by Snehalatha et al. (2011) specifying ladders of services related to quantity, quality, accessibility, continuity and reliability. Another candidate for re-framing the debate might usefully emerge from the intriguing work being conducted on risk-based domestic water security measures (e.g. Bradley \& Bartram, 2013). The attraction of both these approach is that it focuses on measurements of output rather than input and thus provides the potential for communities and other actors, such as NGOs, to experiment with approaches that can reach 


\section{Unpublished manuscript}

appropriate levels of service and/or security. Such a move would bypass the potential for conflict over specified types of technology, thereby reducing the potential for localised political risks such as those examined in this paper. It would also shift the gaze of influential actors away from implementation to a longer view of water services and/or security. It is recognised that the transition from the current situation is limited by technical constraints in terms of measuring service characteristics, but particularly in middle-income countries such as India, holistic monitoring regimes are increasingly feasible. Even without this transition, however, there is need for policy-makers to recognise the limits of the current format which means the politically sensitive task of acknowledging the distance that still needs to be covered to meet the fundamental political ambitions of the MDG for water supply in terms of safe and sustainable water supply services. Such measures may not placate groups that remain staunchly committed to traditionalist methods but it would temper the critiques that governments have become too concerned with installing technology and not concerned enough about ensuring safe and sustainable water supply.

\section{Conclusion}

Through the discourse analysis of documents and examining the opposition to handpumps by two NGOs in Bihar, the paper exposes how technologically deterministic discourse can contribute to conflict and capability traps in rural water supply. From a policy point of view, this is because the current binary indicator poorly reflects the service characteristics of water supply and, so, can lead to a false sense of safety for those using handpumps. Yet, ironically, the critics of this policy also draw on their own technologically deterministic ideas about 


\section{Unpublished manuscript}

water supply, which are echoed in the broad coalition of traditionalist discourse in the Indian public sphere that opposes overly technocratic approaches in the water sector. The associated critique of technological determinism in rural water supply is particular timely with the GoI recently shifting its policy goals. By 2022 , it now aims to "ensure that at least $80 \%$ of rural households have piped water supply with a household connection" (MDWS, 2013). Recognising the scale of investment required, the government has announced a number of large-scale schemes, such as the $\$ 1$ billion project to deliver piped water supply to Bihar and other lagging states (GoI 2014). It is interesting to note that whilst this policy aspires for a drinking water technology that is beyond the improved/unimproved binary, it remains technologically deterministic in its ambition. Raising this point is not highlighted to discourage such investment, which is commended by the authors, but rather to reflect on how the scheme may play out in particular locales and be incorporated into discursive storylines about the future direction of water resources in India. This research suggests that there is a danger that technologically deterministic policy programmes face political risks if local practitioners are faced with an inconsistency between external development storylines about the appropriateness of technology and their own field experiences in which the quality of supply can remain questionable. We have demonstrated this through cataloguing the situation in West Champaran but also highlighting the broader nature of this risk through the analysis of national-level discourses. As an exploratory study, the research raises additional questions regarding the conflation between operational discourses and normative goals in the water sector. In particular, the sector needs to consider the technocratic questions regarding to what extent its monitoring regimes can be reformed to minimise capability traps and whether any new techniques can be developed for identifying sections of the population already stuck in 
such traps? There are also broader questions regarding the limitations and unintended consequences associated with standardisation in the sector (which must be considered when discussing the clear benefits that standardisation can bring in terms of governance and supply chains). Reflecting on and examining such issues will be beneficial for a global water sector that needs to respond to the hidden needs of the billion or so individuals drinking from improved technologies but who remain consuming unsafe water.

\section{LITERATURE CITED}

Agarwal, A., and N. Narain. 1997. Dying Wisdom: Rise, fall and potential of India's water harvesting systems. Centre for Science and Environment. New Delhi.

Andrews, M., L. Pritchett, and M. Woolcock. 2013. Escaping Capability Traps Through Problem Driven Iterative Adaptation (PDIA). World Development. 51:234-244.

Bartram, J. (2008). Improving on haves and have-nots. Nature, 452(7185), 283-4. http://doi.org/10.1038/452283a

Birkenholtz, T. 2008. Contesting expertise: The politics of environmental knowledge in northern Indian groundwater practices. Geoforum. 39(1):466-482.

Bradley, D.J., and J. K. Bartam. 2013. Domestic water and sanitation as water security: monitoring, concepts and strategy. Philosophical Transactions of the Royal Society A. $371: 2002$

Chambers, R. 2008. Revolutions in Development Inquiry. Earthscan, London.

Chaudhuri, S., and V. Gupta. 2009. Levels of Living and Poverty Patterns: a DistrictWise analysis for India. Economic and Political Weekly. 44:9.

Christoff, P. 1996. Ecological modernisation, ecological modernities. Environmental 
Politics. 5(3):476-500.

Clasen, T.F. 2012. Millennium Development Goals water target claim exaggerates achievement. Tropical Medicine \& International Health. 17(10): 1178-1180.

Cleaver, F. 2002. Reinventing institutions: Bricolage and the social embeddedness of natural resource management. The European Journal of Development Research. 14(2): 11-30.

Cleaver, F. 2012. Development through bricolage: rethinking institutions for natural resource management. Routledge. Oxford.

Doulton, H., and K. Brown. 2009. Ten years to prevent catastrophe? Discourses of climate change and international development in the UK press. Global Environmental Change. 19(2):191-202.

Dryzek, J. 2005. The Politics of the Earth: Environmental Discourses. Oxford University Press. Oxford.

Duymedjian, R., and C. C. Ruling. 2010. Towards a Foundation of Bricolage in Organization and Management Theory. Organization Studies. 31(2):133-151.

Fairclough, N. (2003). Analyzing Discourse: Textual Analysis for Social Research. Routledge, London.

Escobar, A. (1997). The Making and Unmaking of the Third World through Development. In The Post-Development Reader (pp. 85-93). http://doi.org/10.1093/mind/102.405.1Faille, D. della. (2011). Discourse analysis in international development studies: Mapping some contemporary contributions. Journal of Multicultural Discourses, 6(3), 215-235. 
http://doi.org/10.1080/17447143.2011.594512

Feindt, P.H., and A. Oels. 2005. Does discourse matter? Discourse analysis in environmental policy making. Journal of Environmental Policy and Planning. 7(3):161173.

Ferguson, J. (1990). The anti-politics machine: development, depoliticization, and bureaucratic power in Lesotho. Cambridge University Press, New York.

Flyvbjerg, B. 2006. Five Misunderstandings About Case-Study Research. Qualitative Inquiry. 12(2):219-245.

Gee, J. P. 1999. An Introduction to Discourse Analysis: Theory and Method. Routledge. London.

Godfrey, S., F. Timo, and M. Smith. 2006. Microbiological risk assessment and management of shallow groundwater sources in Lichinga, Mozambique. Water \& Environment Journal. 20(3):194-202.

Government of India (GoI). 2012. National Water Policy. Ministry of Water Resources. New Delhi.

Gupta, A. 1998. Postcolonial Developments: Agriculture in the Making of Modern India. Duke University Press.

Hajer, M. 1995. The Politics of Environmental Discourse. Oxford University Press. Oxford.

Hajer, M. 2002. Discourse analysis and the study of policy making. European Political Science. 2(1):61-65.

Hajer, M., and W. Versteeg. 2005. A decade of discourse analysis of environmental 
politics: Achievements, challenges, perspectives. Journal of Environmental Policy and Planning. 7(3):175-184.

Jacob, N. 2008. Jalyatra: Exploring India's Traditional Water Management Systems. Penguin, New Delhi.

Jal Jan Jodo Abhiyaan 2013. 'Jal Jan Jodo Abhiyaan' - Concept Note. Jal Jan Jodo Abhiyaan. Jaipur.

Joint Monitoring Programme for Water Supply and Sanitation WHO/UNICEF. 2012. Progress on Sanitation and Drinking-Water: 2012 Update. World Health Organization. Geneva.

Joint Monitoring Programme for Water Supply and Sanitation WHO/UNICEF. 2014. Improved and unimproved water and sanitation facilities. (online). Available at: http://www.wssinfo.org/definitions-methods/watsan-categories/ (accessed Jan, 10).

Levi-Strauss, C. 1966. The Savage Mind (English Translation from La Pensee sauvage). Chicago University Press. Chicago.

Lloyd, B. J., and R. Helmer. 1991. Surveillance of drinking water quality in rural areas. Longman Scientific \& Technical. London.

Mackenzie, D. (1984). Marx and the Machine. Technology and Culture, 25(3), 473-502. http://doi.org/10.2307/3104202

Ministry of Drinking Water and Sanitation 2013. National Rural Drinking Water Programme, Rajiv Gandhi Drinking Water Mission, Movement towards ensuring people's Drinking Water Security in Rural India, Framework for Implementation (updated 2013). Government of India. New Delhi. 
Merrey, D. J., R. Meinzen-Dick, P. Mollinga, and E. Karar. 2007. 'Policy and Institutional Reform: the Art of the Possible'. In. Molden, D. (ed.). Water for food, Water for Life: A Comprehensive Assessment of Water Management in Agriculture. Earthscan. London.

Moriarty, P., S. Smits, J. Butterworth, and R. Franceys. 2013. Trends in Rural Water Supply: Towards a Service Delivery Approach. Water Alternatives. 6(3):329-349.

Megh Pyne Abhiyan (MPA). 2011. Towards self-reliance and access to safe drinking water and secure sanitation in North Bihar. Megh Pyne Abhiyan. Patna.

Megh Pyne Abhiyan (MPA). 2012. Dug Wells - A Potential Safe Source of Drinking water for Arsenic and Iron contaminated region in North Bihar. Megh Pyne Abhiyan. Patna.

Onda, K., J. Lobuglio, and J. Bartram. 2012. Global access to safe water: Accounting for water quality and the resulting impact on MDG progress. International Journal of Environmental Research and Public Health. 9(3):880-894.

Parker, A. H., R. Youlten, M. Dillon, T. Nussbaumer, R.C. Carter, S.F. Tyrrel, and J. Webster. 2010. An assessment of microbiological water quality of six water source categories in north-east Uganda. Journal of Water and Health. 8(3):550-560.

Prasad, E., K. L. Joy, S. Paranjape, and S, Vispute. 2012. Agony of Floods: Flood Induced Conflict in India. Forum for Policy Dialogue on Water Conflicts in India. Pune.

Pritchett, L., M, Woolcock, and M. Andrews. 2013. Looking Like a State: Techniques of Persistent Failure in State Capability for Implementation. Journal of Development Studies. 49(1):1-18. 
Scott, J. 1998. Seeing Like a State: How Certain Schemes to Improve the Human Condition Have Failed. Yale University Press. New Haven: CT.

Shan, P. 2010. Waterman' becomes Ganga's saviour. The Times of India. (Online). Available $\quad$ at: $\quad$ http://articles.timesofindia.indiatimes.com/2010-0905/lucknow/28251496_1_ganga-action-plan-gangasagar-hunger-strike (accessed Sept, 09).

Singh, R. 2013. Let us come forward to fulfill the dreams of Gandhi ji!. Tarun Bharat $\begin{array}{lll}\text { Sangh. } & \text { (Online). } & \text { Available }\end{array}$ http://www.tarunbharatsangh.org/pdf/waterman's\%20view/ENGLISH$\% 20$ Let $\% 20$ us $\% 20$ come $\% 20$ forward $\% 20$ to $\% 20$ fulfill $\% 20$ the $\% 20$ dreams $\% 20$ of $\% 20$ Gand hi\%20ji.pdf (accessed August/04).

Sinha, C.P. 2011. Climate change and its impacts on the wetlands of North Bihar, India. Lakes \& Reservoirs: Research \& Management. 16 (2):109-111.

Slaymaker, T. and Fonesca, C. (2012). Framing Paper for the JMP post-2015 Working Group on Water. Working Paper for the JMP Working Group on Water. WaterAid and IRC. Available from: http://www.wssinfo.org/fileadmin/user_upload/resources/post-2015-WaterWorking-Group-Framing-Paper-v3.pdf

Snehalatha M., P. Busenna, V. Ratna Reddy, and V Anitha. 2011. Rural Drinking Water Service Levels: A Study of Andhra Pradesh, South India. Working Paper No.105 WASHCost. Centre for Economic and Social Studies. Hyderabad.

Smith, M. R., \& Marx, L. (1994). Does Technology Drive History?: The Dilemma of 
Technological Determinism. MIT Press. Retrieved from

https://books.google.com/books?id=WWztFfsA-QEC\&pgis=1

Somanathan, E. 2013. Are embankments a good flood control strategy? A case study on the Kosi river. Water Policy. 15(1):75.

Srikanth, R. 2013. Access, monitoring and intervention challenges in the provision of safe drinking water in rural Bihar, India. Journal of Water, Sanitation and Hygiene for Development. 3(1):61-69.

The Lancet. 2014. Water and sanitation: addressing inequalities. Lancet. 383(9926):1359.

Uphoff, N. 1986. Local Institutional Development: An Analytical Sourcebook with Cases. Kumarian. West Hartford, CT.

Velázquez Gomar, J.O. 2014. International targets and environmental policy integration: The 2010 Biodiversity Target and its impact on international policy and national implementation in Latin America and the Caribbean. Global Environmental Change. 29:202-212. 